\title{
Application of Fuzzy Time Series (FTS) Algorithm in Production Planning of Indonesia's Oil Refining Company
}

\author{
Zakka Ugih Rizqi ${ }^{1}$, Tommy Aries Kurniawan ${ }^{2}$, Adinda Khairunisa ${ }^{2}$ \\ ${ }^{1}$ Department of Industrial Management, National Taiwan University of Science and Technology, Taiwan \\ 2,3 Department of Industrial Engineering, Universitas Islam Indonesia, Indonesia
}

\begin{abstract}
Forecasting and aggregate planning are crucial phases in production planning especially for oil refining company that takes expensive production cost. Accurate forecasting greatly influences the success of production planning since it is the starting point of production planning. Whereas aggregate planning becomes important because it functions to bridge between the demand or production target with the existing resource requirements. Seeing the importance of accurate forecasting and aggregate planning, this research emphasizes the use of Fuzzy Time Series (FTS) Algorithm to forecast Premium sales in Indonesia's oil refining company. The comparison is also done between FTS with the other classical techniques in time series forecasting to test the reliability of algorithm and FTS outperforms the others based on the lowest MAPE value as much as $0.87 \%$. FTS result is then used as an input in the aggregate planning by using heuristics method and comparing 3 strategies which are Level Strategy, Chase Strategy, and Hybrid Strategy. The result shows that Hybrid Strategy is the most efficient one because it produces the lowest production cost for three months production period as much as Rp 3,272,000,000.
\end{abstract}

\section{CONTACT}

ugihzakka@gmail.com

\section{KEYWORDS}

Aggregate Planning, Forecasting,

Fuzzy Time Series, Production

Planning.

\section{INTRODUCTION}

Z Company is one of the Republic of Indonesia State-Owned Enterprises (BUMN) companies that focuses on oil and energy processing. In order to meet the demand, Z Company has 6 refinery units spread across Indonesia. One of the processes carried out is refining crude oil and naptha into fuel oil (BBM) and one of its products is Premium. Premium is very popular in Indonesia and in high demand in 2019. It is relatively cheap price since it receives subsidies from the state budget. Even tough there is an issue that Premium production will be stopped due to bad impact for environment, but this research will still be useful by proposing an approach for accurate production planning applicable for other products.

Seeing the large amount of Premium demand so that good planning is needed starting from accurate sales forecasting to effective aggregate planning strategies to allocate the capacity of the resources that are owned to meet the predicted demand so as to minimize production costs. With accurate sales forecasting, material requirements planning (MRP) and production scheduling will be effective which ultimately can satisfy the customer's desires [1].

At present, forecasting by Z Company uses qualitative methods which only rely on intuition from the expert so that the accuracy cannot be known and the subjectivity is very high. It will be very risky for the failure of planning. In this study, forecasting for the next 3 months namely March, April and May 2019 will be done using Fuzzy Time Series (FTS)-based Algorithm which is compared with other methods. Then, the most accurate forecasting method will be used as input in aggregate planning using the heuristics or graphical method so that low production costs can be obtained to meet Premium sales forecasting.

A similar study was conducted by Gansterer (2015) [2] who used time series-based forecasting which is then continued with aggregate planning using the simulation model. Mantilla et al. (2017) [3] conducted aggregate planning by evaluating 2 strategies, namely Zero inventory and Vary Inventory with input demand obtained from MPS. Fajar and Lestari (2017) [4] conducted aggregate planning using Model 2 and Model 4 introduced by Heizer (2008) [5]. Whereas Gulsun et al. (2009) [6] conducted forecasting using the multiplicative decomposition model with trends and seasonal patterns which is then continued with aggregate planning using Linear Physical Programming method. Compared to previous research, it has not been studied about forecasting using the FTSbased Algorithm which is then continued with heuristic-based aggregate planning especially applied in Oil Refining Company. 


\section{RESEARCH METHODS}

\section{Data Collecting}

Table 1 shows the historical data obtained from the company report. The amount of data in forecasting greatly determines the accuracy of the forecasting. Therefore, it is necessary to test the adequacy of data using Equation (1) [7]. Furthermore, production cost data can be seen in Table 2 that will be used in aggregate planning stage.

Table 1. Historical data of premium sales.

\begin{tabular}{|c|c|c|}
\hline Year & Month & Sales (Bbl) \\
\hline \multirow{12}{*}{2017} & January & 1234978 \\
\hline & February & 1141208 \\
\hline & March & 1221152 \\
\hline & April & 1680000 \\
\hline & May & 1155200 \\
\hline & June & 1686000 \\
\hline & July & 1191795 \\
\hline & August & 839697 \\
\hline & September & 748980 \\
\hline & October & 1392589 \\
\hline & November & 1260000 \\
\hline & December & 1456878 \\
\hline \multirow{12}{*}{2018} & January & 1463200 \\
\hline & February & 1342732 \\
\hline & March & 1476973 \\
\hline & April & 1458491 \\
\hline & May & 1451971 \\
\hline & June & 1265833 \\
\hline & July & 1234986 \\
\hline & August & 1036640 \\
\hline & September & 1076410 \\
\hline & October & 1260026 \\
\hline & November & 1303500 \\
\hline & December & 1348500 \\
\hline \multirow{2}{*}{2019} & January & 1200000 \\
\hline & February & 1349992 \\
\hline
\end{tabular}

Table 2. Production cost data.

\begin{tabular}{ll}
\hline \multicolumn{1}{c}{ Data } & Cost (Rupiah) \\
\hline Refinery Worker Cost & $3,000,000 /$ Month \\
Outsourcing Worker Cost & $3,500,000 /$ Month \\
Inventory Cost & $8,500 /$ Bbl/Month \\
\hline \multicolumn{2}{c}{$\mathrm{N}^{\prime}=\left(\frac{\frac{k}{s} \sqrt{N \sum X^{2}-\left(\sum X\right)^{2}}}{\sum X}\right)^{2}$}
\end{tabular}

By using $95 \%$ confidence level $(\mathrm{k})$ and a degree of accuracy (s) of 10\%, calculate with formula 1 , it is obtained $\mathrm{N}^{\prime}=10.8$ which is less than $26(\mathrm{~N})$. Because $\mathrm{N}^{\prime}<\mathrm{N}$, then it can be said that 26 historical data are sufficient enough to be used as the basis for time-series analysis. It is worth noting that forecasting result will be poor if time horizon is too long. Therefore, in this research, the time horizon is determined only for the next 3 months namely March, April, and May 2019. 
Z Company also has several company policies including safety stock $=50,000 \mathrm{Bbl} /$ month, Z Company does not recruit new workers and lay off workers for production needs in the refinery, but will be outsourced. The company also does not subcontract if it is unable to fulfill a number of requests, but will try to increase production capacity as requested. If the production capacity is still not fulfilled, the company will allow stockout. At present, Z Company has 120 workers/day, which in one day is divided into 3 shifts, each shift working for 8 hours. To determine the ability of workers in Premium production, obtained from the production rate in February 2019 amounted to $1349992 \mathrm{Bbl} / 28$ days $=48214 \mathrm{Bbl} /$ day $=48214 \mathrm{Bbl} / 24$ hours $=2008.9 \mathrm{Bbl} /$ hour. The number of workers per day in February 2019 is 154 workers, so each worker can produce $=2008.9 \mathrm{Bbl} /$ hour $/ 154=13$ $\mathrm{Bbl} /$ hour. So, it takes 0.077 hour for workers to produce $1 \mathrm{Bbl}$ Premium.

In order to test the reliability of algorithm, comparison analysis is needed. Since historical data have a horizontal pattern, the other methods are also used that are suitable for forecasting with horizontal data pattern like moving average (MA), weighted moving average (WMA) and single exponential smoothing (SES). The main difference between the FTS-based algorithm of a time series and classical time series or even machine learning and deep learning is that the values are represented by fuzzy sets rather than real crisp values. The error measurement used are Mean Absolute Deviation (MAD) and Mean Absolute Percentage Error (MAPE) with formula shown in Equation (2) dan Equation (3) [5]. At informs actual data in t period, Ft informs forecasting data in $\mathrm{t}$ period, and $\mathrm{n}$ informs number of historical data used.

$$
\begin{aligned}
& \mathrm{MAD}=1 / n \times \Sigma|A t-F t| \\
& \mathrm{MAPE}=(100 / n) \times \Sigma(|A t-F t| / A t)
\end{aligned}
$$

\section{Forecasting Using FTS Algorithm}

The FTS Algorithm is a forecasting technique that follows fuzzy theory to predict uncertainty in the future. There are some FTS algorithms proposed by researchers since it gives promising results, some of them are developed by Cheng et al. [8], Qiu et al. [9], Cagcag et al. [10], Liu et al. [11], Hwang et al. [12] and Lee \& Chou [13]. The difference may happen in determining interval length to form fuzzy logical relationships and or fuzzy logical relationship groups, level of order, But, in this research, FTS algorithm developed by Jasim et al. [14] is used. The reason because it belongs to the first order and time-variant methods that sometimes give better result. Then the calculation is done by following these steps [15] [16].

1. Determining the Universe of Discourse $(\mathrm{U})$ :

$\mathrm{U}=[748000,1686000]$

2. Calculating the length of the interval (I) using the average based length method, obtained I is 2000 .

3. Determining the fuzzy interval (ui) based on length of interval (I) with the middle value (di):

$$
\begin{array}{clll}
\text { u1 } & =[748000,750000] ; & \mathrm{d} 1 & =749000 \\
\mathrm{u} 2 & =[750000,752000] ; & \mathrm{d} 2 & =751000 \\
\mathrm{u} 3 & =[752000,754000] ; & \mathrm{d} 3 & =753000 \\
\vdots & & \vdots & \\
\mathrm{u} 468 & =[1682000,1684000] ; & \mathrm{d} 468 & =1683000 \\
\mathrm{u} 469 & =[1684000,1686000] ; & \mathrm{d} 469 & =1685000
\end{array}
$$

4. Determining the fuzzy set (Ai) showed in Table 3.

5. Determining Fuzzy Logical Relations (FLR) showed in Table 4. FLR is described as $A j \rightarrow A i$, where the left side is called the current state and the right side is called the next state.

6. Determining Fuzzy Logical Relationship Group (FLRG) showed in Table 5. FLRG is formed to see the tendency of changes in data from certain state to the next state which will later determine the results of forecasting.

7. Calculating forecasting results. In this step, certain provisions are used as described in previous research [10]. 
Table 3. Fuzzification of historical data.

\begin{tabular}{|c|c|c|c|}
\hline $\begin{array}{c}\text { Yea } \\
\text { r }\end{array}$ & Period & $\begin{array}{l}\text { Sales } \\
\text { (Bbl) }\end{array}$ & Fuzzification \\
\hline \multirow{12}{*}{2017} & January & 1234978 & A244 \\
\hline & February & 1141208 & A197 \\
\hline & March & 1221152 & A237 \\
\hline & April & 1680000 & A 467 \\
\hline & May & 1155200 & A204 \\
\hline & June & 1686000 & A469 \\
\hline & July & 1191795 & A222 \\
\hline & August & 839697 & A46 \\
\hline & September & 748980 & A1 \\
\hline & October & 1392589 & A323 \\
\hline & November & 1260000 & A257 \\
\hline & December & 1456878 & A355 \\
\hline \multirow{12}{*}{2018} & January & 1463200 & A358 \\
\hline & February & 1342732 & A298 \\
\hline & March & 1476973 & A365 \\
\hline & April & 1458491 & A356 \\
\hline & May & 1451971 & A352 \\
\hline & June & 1265833 & A259 \\
\hline & July & 1234986 & A244 \\
\hline & August & 1036640 & A145 \\
\hline & September & 1076410 & A165 \\
\hline & October & 1260026 & A257 \\
\hline & November & 1303500 & A278 \\
\hline & December & 1348500 & A301 \\
\hline \multirow{2}{*}{2019} & January & 1200000 & A227 \\
\hline & February & 1349992 & A301 \\
\hline
\end{tabular}

Table 4. Fuzzy logical relations (FLR).

\begin{tabular}{ll}
\hline \multicolumn{1}{c}{ Time } & \multicolumn{1}{c}{ FLR } \\
\hline January $\rightarrow$ February & A244 $\rightarrow$ A197 \\
February $\rightarrow$ March & A197 $\rightarrow$ A237 \\
March $\rightarrow$ April & A237 $\rightarrow$ A467 \\
April $\rightarrow$ May & A467 $\rightarrow$ A204 \\
May $\rightarrow$ June & A204 $\rightarrow$ A469 \\
June $\rightarrow$ July & A469 $\rightarrow$ A222 \\
July $\rightarrow$ August & A222 $\rightarrow$ A46 \\
August $\rightarrow$ September & A46 $\rightarrow$ A1 \\
\hline
\end{tabular}

Table 5. Fuzzy logical relationship group (FLRG).

\begin{tabular}{ll}
\multicolumn{1}{c}{$\begin{array}{c}\text { Current } \\
\text { State (Ai) }\end{array}$} & \multicolumn{1}{c}{ Next $\mathbf{c}(\mathbf{A j})$} \\
\hline A1 & A323 \\
A46 & A1 \\
A145 & A165 \\
\hline A165 & A257 \\
A197 & A237 \\
A204 & A469 \\
A222 & A46 \\
A227 & A301 \\
A237 & A467 \\
A244 & A145, A197 \\
A257 & A278, A355 \\
A259 & A244 \\
A278 & A301 \\
A298 & A365 \\
A301 & A227 \\
A323 & A257 \\
A352 & A259 \\
A355 & A358 \\
A356 & A352 \\
A358 & A298 \\
\hline A365 & A356 \\
A467 & A204 \\
A469 & A222 \\
\hline
\end{tabular}

\section{Aggregate Planning}

In this research, aggregate planning is carried out using graphical method, where cost calculations will be carried out using strategies as follows [17].

1. Level strategy: the amount of production is fixed and the inventory that arises can be used to meet the excess demand for the product for a certain period.

2. Chase strategy: this strategy provides that the amount of production is equal to the number of demands.

3. Hybrid strategy: this strategy is a combination of level strategy and chase strategy. Where in this case, the amount of production is obtained from a minimum of the existing forecasting value. In certain circumstances, it can change according to company policy. 


\section{Researh Flowchart}

Figure 1 shows the steps carried out in this research.

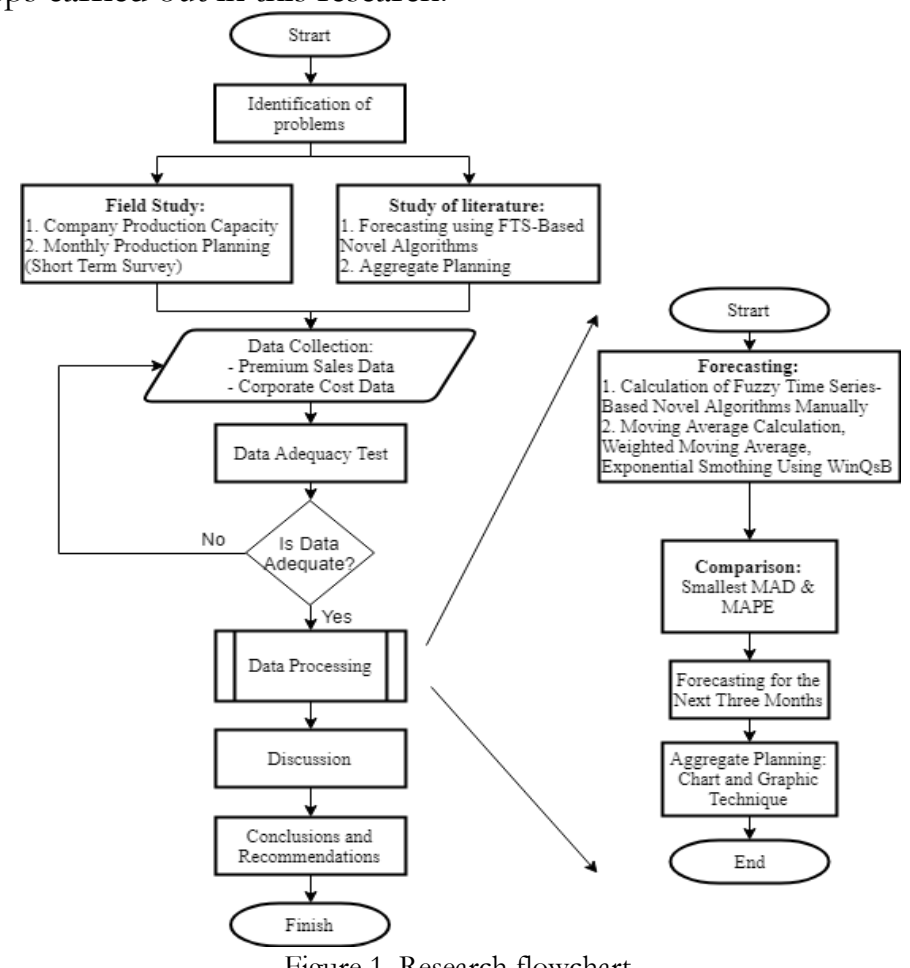

Figure 1. Research flowchart.

\section{RESULTS AND DISCUSSIONS}

\section{Forecasting Results}

The four methods used for forecasting are FTS, MA with $\mathrm{M}=3$, WMA with $\mathrm{M}=4$ (W1 $=0.4$, W2 $=0.3$, W3 $=0.2$, and W4 $=0.1$ ), and SES (alpha $=0.8$ ). The result of forecasting will be displayed as graphic that can be seen in Figure 2. Testing the level of accuracy is done by comparing the measurement criteria for Mean Absolute Deviation (MAD) and Mean Absolute Percentage Error (MAPE) in Table 6. Table 6 shows that FTS have significantly smaller MAD and MAPE values than other methods. Then, FTS result will be used to predict the period of March 2019 until May 2019 which is then used as input in aggregate planning shown in Table 7.

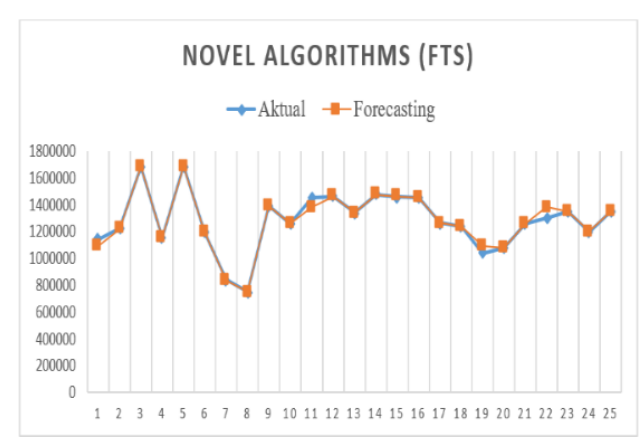

a.

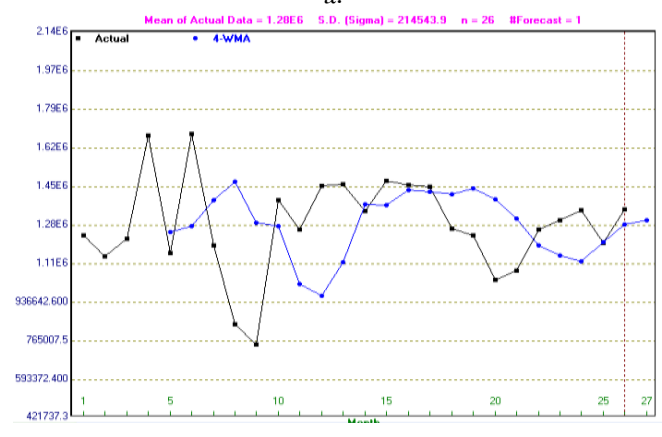

c.
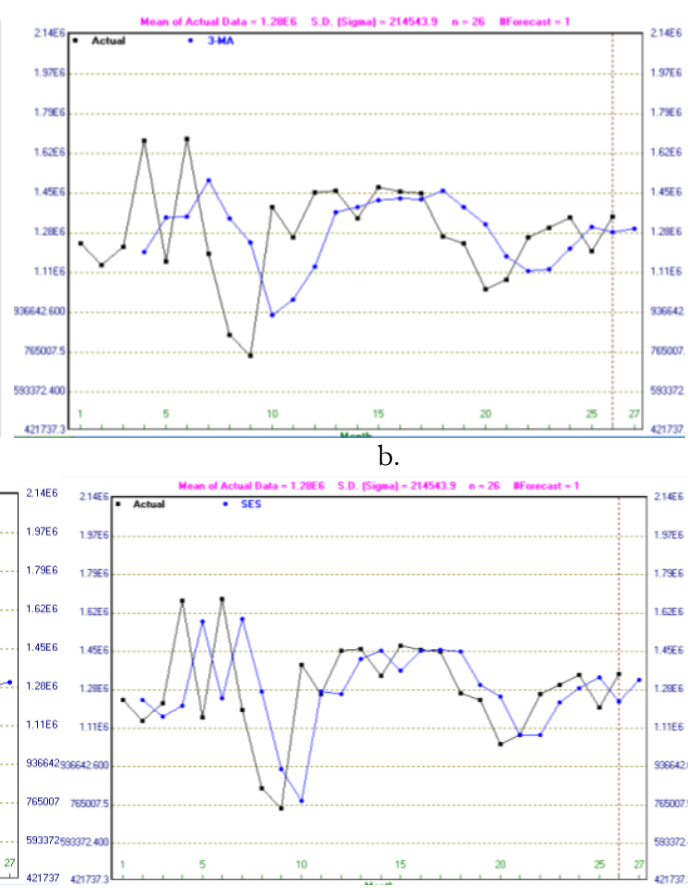

d.

Figure 2. Forecasting results (a) FTS (b) MA (c) WMA (d) SES. 
Table 6. Accuracy testing.

\begin{tabular}{lll}
\hline Method & MAD & MAPE \\
\hline FTS & 10824 & $0,87 \%$ \\
Moving Average & 217163 & $18,5 \%$ \\
Weighted Moving Average & 215581 & $19,09 \%$ \\
Single Exponential Smoothing & 186504 & $15,13 \%$ \\
\hline
\end{tabular}

Table 7. Demand for march to may 2019

\begin{tabular}{ll}
\hline Month & Forecasting Result (Bbl) \\
\hline March 2019 & 1200500 \\
April 2019 & 1349000 \\
May 2019 & 1200500 \\
\hline
\end{tabular}

\section{Aggregate PlanningRresults}

\section{- Level Strategy}

In this strategy, the amount produced in everyday is the same as the average sales forecast. Average Requirement $=(1200500+1349000+1349000) / 92=40760,869 \mathrm{Bbl} /$ day and initial inventory in March $=148000 \mathrm{Bbl}$. The table of calculation of level strategy can be seen in Table 8 and the graphic produced if the company implements level strategy showed in Figure 3.

Table 8. Level strategy calculation.

\begin{tabular}{lllll}
\hline Month & Production Days & Production/Mo & Inventory (Bbl) & Total Inventory (Bbl) \\
\hline March & 31 & 1263586 & 63086 & 211087 \\
April & 30 & 1222826 & -126173 & 84913 \\
May & 31 & 1263586 & 63086 & 148000 \\
& Total & 3750000 & - & 444000 \\
\hline
\end{tabular}

The number of workers needed per day $=(40760,869 \times 0.077) / 24=131$ workers / day. Because the total number of workers at Z Company is 120 people / day, it is necessary to outsource 11 workers. Then the results of cost calculation at the level strategy are as follows:

- Cost of Inventory $=$ Total inventory $\mathrm{x}$ Inventory Cost $=444,000 \times 8,500=\mathrm{Rp} 3,774,000,000$.

- Cost of Worker $=$ (Refinary cost $\mathrm{x}$ Number of workers $\mathrm{x}$ Month works) + (Outsourcing worker cost x Number of outsourcing workers x Month works $)=(3$ million x $120 \times 3)+(3.5$ million $\times 11 \times 3)=\operatorname{Rp~1,195,500,000.~}$

So that the total production cost obtained amounted to $\mathrm{Rp} 4,969,500,000$.

\section{- Chase Strategy}

The table of calculation of chase strategy can be seen in Table 9 and the graphic produced if the company implements a chase strategy showed in Figure 4. With the same calculation as at the level strategy. The total production cost obtained in the chase strategy is Rp 4,976,500,000.

Table 9. Chase strategy calculation.

\begin{tabular}{lllll}
\hline Month & Production Days & Production/Mo & Inventory (Bbl) & Total Inventory (Bbl) \\
\hline March & 31 & 1200500 & 0 & 148000 \\
April & 30 & 1349000 & 0 & 148000 \\
May & 31 & 1200500 & 0 & 148000 \\
\hline
\end{tabular}

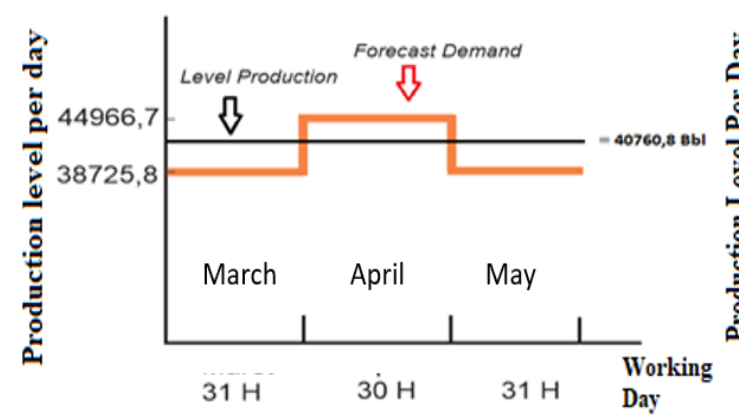

Figure 3. Level strategy graphic.

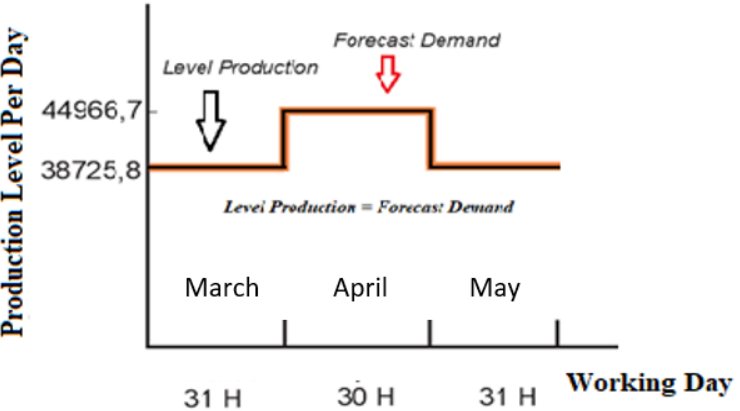

Figure 4. Chase strategy graphic. 


\section{- Hybrid strategy}

In a hybrid strategy, the company produces production with the same amount of production as the minimum number of forecasting, which is $1,200,500 \mathrm{Bbl}$ per month. The table of calculation of hybrid strategy can be seen in Table 10 and the graphic produced if the company implements a hybrid strategy showed in Figure 5.

Table 10. Hybrid strategy calculation.

\begin{tabular}{lccrr}
\hline & Production Days & Production/Mo & Inventory (Bbl) & Total Inventory (Bbl) \\
\hline March & 31 & 1200500 & 0 & 148000 \\
April & 30 & 1200500 & -148500 & $-(500)$ \\
May & 31 & 1200500 & 0 & 0 \\
\hline
\end{tabular}

Because the company has a safety stock policy of $50,000 \mathrm{Bbl} /$ month, the strategy needs to be revised. Then the solution is to increase the level of production to meet the policy. Therefore, in April 2019 a total of production is $1,200,500+50,500=1,251,000$. Revision of this strategy can be seen in Figure 6. With the same calculation as at the level strategy. The total production cost obtained in the hybrid strategy is $\mathrm{Rp} 3,272,000,000$.

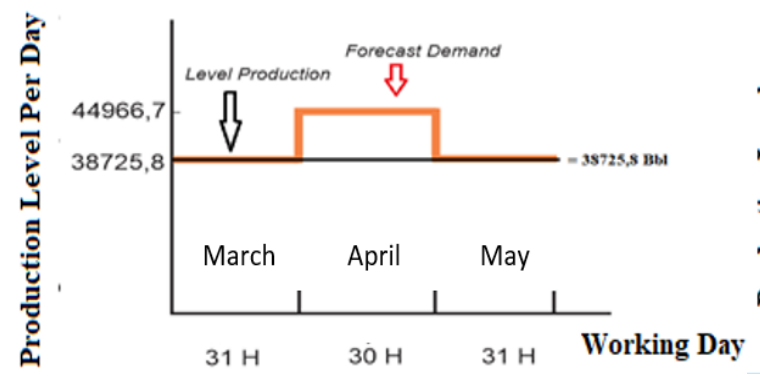

Figure 5. Hybrid strategy graphic.

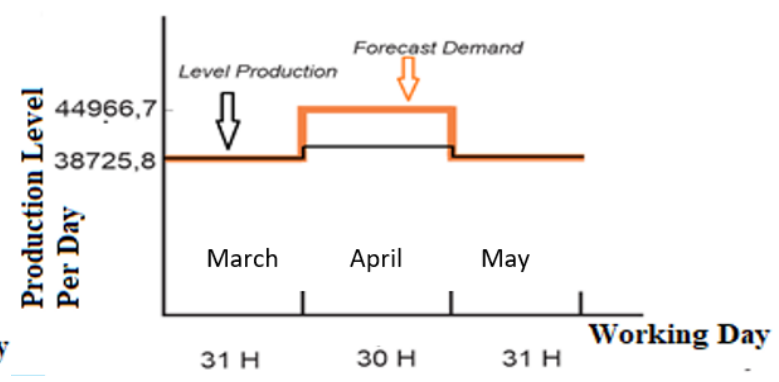

Figure 6. Revised hybird strategy graphic.

\section{Discussion}

From the result of forecasting using FTS, it can be seen that this method is more accurate than the other methods. The company can use this method in forecasting Premium sales with very high accuracy, where the amount of MAPE is only $0.87 \%$. From the results of aggregate planning, it was found that the lowest production costs could be achieved by using a hybrid strategy where the company produces Premium at the lowest forecasting value, then if there is a stockout and shortages of stocks beyond the safety stock limit (such as in April 2019) then the solution is to increase production capacity, this is because Z Company does not do subcontract, so increasing production capacity is the right choice. The implementation of the hybrid strategy only costs as much as Rp 3,272,000,000 for the next 3 months. The comparison between the 3 strategies in aggregate planning at $Z$ can be seen in Table 11.

Table 11. Comparison of aggregate planning strategies.

\begin{tabular}{lrrr}
\hline \multicolumn{1}{c}{ Category } & \multicolumn{1}{c}{ Level Strategy } & Chase Strategy & \multicolumn{1}{c}{ Hybrid Strategy } \\
\hline Inv. Cost $(\mathrm{Rp})$ & $3,774,000,000$ & $3,774,000,000$ & $2,108,000,000$ \\
Worker Cost $(\mathrm{Rp})$ & $1,195,500,000$ & $1,202,500,000$ & $1,164,000,000$ \\
Stock Left $(\mathrm{Bbl})$ & 148,000 & 148,000 & 50,000 \\
\hline
\end{tabular}

\section{CONCLUSIONS}

From the results of the previous discussion, it can be taken from this research that the FTS method has a significantly more accurate than the moving average (MA), weighted moving average (WMA) and single exponential smoothing (SES). With MAPE $=0.87 \%$ and MAD $=10824$ in forecasting Premium sales, The number of Premium sales for the March, April and May 2019 that must be fulfilled based on the FTS is $1200500 \mathrm{Bbl}$, $1349000 \mathrm{Bbl}$ and $1200500 \mathrm{Bbl}$ in sequence. Based on the results of aggregate planning using heuristics or graphical method, it is found that the lowest production costs can be achieved by the company using a hybrid strategy, which produces Premium at the lowest forecasting amount of $1200500 \mathrm{Bbl}$ every March and May. However, in April there was a stockout and exceeded safety stock limit so that the level production in April was $1251000 \mathrm{Bbl}$. The implementation of hybrid strategy can produce production costs of Rp 3,272,000,000 which is $34.3 \%$ lower than the chase strategy and lower by $34.2 \%$ compared to level strategy. The proposed approach in this research also can be used for other products to enhance production planning, not only Premium. 


\section{ACKNOWLEGDEMENTS}

First of all, the authors must acknowledge the gratitude to Allah, the Ever Magnificent and Enormous. This work would have never become true, without His blessing and guidance. Authors also thank the company for the opportunity given a place to apply the ability of authors related to the science of industrial engineering.

\section{REFERENCES}

[1] Gasperz V. Production Planning and Inventory Control; Jakarta: PT Gramedia Pustaka Utama, 2008

[2] Gansterer M. Aggregate planning and forecasting in make-to-order production systems International Journal of Production Economics 2015; 150: 521-528.

[3] Mantilla CR, Sailema MS, Rosere CS, Pozo RG. Aggregate production planning, case study in a mediumsized industry of the rubber production line in Ecuador. IOP Conf. Ser.: Mater. Sci. Eng 2017; 212: 1-5.

[4] Fajar M, Lestari YD. Aggregate planning analysis in PT. Akebono Brake Astra Indonesia. Journal of Business and Management 2017; 6: 182-191.

[5] Heizer JH, Render B. Operations Management, New Jersey: Pearson Prentice Hall, 2008.

[6] Gulsun B, Tuzkaya G, Tuzkaya UR, Onut S. An aggregate production planning strategy selection methodology based on linear physical programming. International Journal of Industrial Engineering 2009; 16: 135 146.

[7] Wignjosoebroto S. Ergonomi, Studi Gerak dan Waktu; Surabaya: Guna Widya, 1995.

[8] Cheng, C, Chen T, Teoh H, Chiang C. Fuzzy time-series based on adaptive expectation model for TAIEX forecasting. Expert Systems with Applications 2008; 34: 1126-1132.

[9] Qiu W, Zhang P, Wang Y. Fuzzy Time Series Forecasting Model Based on Automatic Clustering Techniques and Generalized Fuzzy Logical Relationship. Mathematical Problems in Engineering 2015: 1-8.

[10] Cagcag O, Yolcu U, Egrioglu E., Aladag CH. High order fuzzy time series forecasting method based on an intersection operation. Applied Mathematical Modelling 2016; 40: 8750-8765.

[11] Liu HT. An improved fuzzy time series forecasting method using trapezoidal fuzzy numbers. Fuzay Optimization and Decision Making 2007; 6: 63-80.

[12] Hwang JR, Chen SM, Lee CH. Handling forecasting problems using fuzzy time series. Fuz:y Sets and System 1998; 100: 217-228.

[13] Lee HS, Chou MT. Fuzzy forecasting based on fuzzy time series. International Journal of Computer Mathematics 2004; 81: 781-789.

[14] Jasim HT, Salim AGJ, Ibraheem KI. A novel algorithm to forecast enrollment based on fuzzy time series. International Journal of Applicaions and Applied Mathematics 2012; 7: 385-397.

[15] Chen SM, Hsu CC. A new method to forecast enrollments using fuzzy time series. International Journal of Applied Science and Engineering 2004; 3: 234-244.

[16] Song Q, Chissom B. Forecasting enrollments with fuzzy time series part II. Fuzzy Sets and System 1994; 62: $1-8$.

[17] Sule DR. Production Planning and Industrial Scheduling, 2nd Edition; United States of America: CRC Press Taylor \& Francais Group, 2007. 